\title{
Effect of scent on comfort of aircraft passengers
}

\author{
Xinhe Yao*, Yu Song and Peter Vink \\ Faculty of Industrial Design Engineering, Delft University of Technology, The Netherlands
}

\begin{abstract}
.
BACKGROUND: Scents may influence the perceived comfort of an environment. There are only a few studies conducted on the relationship between scent and comfort in aircraft cabin.

OBJECTIVE: The goal of this research is to explore whether relationships between scents and perceived comfort can be found for passengers in an aircraft cabin.

METHODS: 276 participants joined an experiment in a Boeing 737 fuselage. The participants were divided into nine groups and each joined a session for 60 minutes with the exposure to different scents. The effect of the odor was measured by a set of questionnaires at the beginning and at the end of the session. Results of questionnaires were analyzed regarding the effects on the completion time, of the type of scents, of the intensity of the scent and on gender.

RESULTS: Significant differences were found at the beginning and at the end of the experiment regarding comfort and emotion, but sometimes no relations could be established. The influence of different scents on comfort/discomfort varied and changed over time. However, in all scenarios, participant' scores on emotion decreased. Additionally, the added scents influenced the linearity between the changes in comfort and discomfort.

CONCLUSIONS: Smell could influence the perceived comfort/discomfort of aircraft passengers over time, and different types of smells have different effects on passengers. The preferences on scents are diverse, which highlights the need for personalization in aircraft cabin design.
\end{abstract}

Keywords: Smell, comfort, discomfort, emotion, aircraft cabin environment

\section{Introduction}

Travelling by air has been becoming more affordable and more popular [1]. Offering a better comfort experience to passengers is of interest to the airlines, as a correlation has been found between the comfort of an aircraft cabin and the user's preference of "flying again with the same airline" [2].

Vink and Hallbeck [3] defined comfort as: "a pleasant state or relaxed feeling of a human being in reaction to its environment". Therefore, comfort can be seen as an effect of physical stimuli and the physical, mental, emotional and social states of a subject over time. In the past decades, many studies have been conducted to explore different physical stimuli

\footnotetext{
*Address for correspondence: Xinhe Yao, Faculty of Industrial Design Engineering, Delft University of Technology, Landbergstraat 15, 2628 CE, The Netherlands. E-mail: x.yao$1 @$ tudelft.nl.
}

that may influence passenger comfort. For instance, Krist [4] and Bubb [5] stated that comfort is influenced by six factors: anthropometry, climate, sound, vibrations, light and smell for automotive passengers. Among those factors, smell was considered to be one of the basic influential aspects. It is placed as the base of the discomfort pyramid [6]. Bouwens et al. [2] also explored the importance of those factors for aircraft passengers and they ranked smell as the third most important factor regarding their experience on aircraft interior comfort. Additionally, they found that smell could influence people's experience unconsciously [7].

Smell is everywhere in the human daily life, and it is one of the ways to communicate with the surrounding environment, i.e. identifying species and detecting danger [8]. Different odor compounds are sensed by odor receptors located in the nose after exhalation and then processed by the brain. 
Meanwhile, odor compounds can also be absorbed through skin and influence brain neurotransmitter and hormone levels [9]. These signals are then communicated to higher cortex regions, which manages conscious thoughts process, before moving into the limbic system and producing sensational physical behavior [10].

Smell may influence the mental state of a subject. For instance, the stress biomarkers, dehydroepiandrosterone, oxidative stress, estradiol, dopamine, cutaneous barrier, sebum secretion and the cutaneous immune system of human are all influenced by olfactory [11]. In folk medicine as well as in aromatherapy, essential oils and fragrance compounds are widely used as a solution for labor pain, chemotherapy side effects, rehabilitation of cardiac patients, restless sleep and post-surgical discomfort [12].

Smell may also change the emotional state of the subject by influencing mood, evoking powerful experiences of pleasure or displeasure, producing alertness or relaxation, and evoking long-forgotten emotional memories [13]. In 1986, Gibbons found that olfactory functions may be able to evoke particular memories and emotions in a more direct way than other senses [14]. Lieff and Alper [15] also described olfactory as "our most emotional sense", which could be explained by the neural structure involved in odor signal processing, as the neuroanatomy of olfactory is intertwined with emotion processing regions in the brain [16].

Smell is also related to the social behavior of human beings. Research showed that natural body odor informs social judgments about health, gender, sexual orientation, and even individual identity [17]. People are more prosocial and willing to help others in the environment with pleasant ambient fragrance [18]. Trust can also be enhanced implicitly via undetected smells [19].

In short, smell may influence the perceived comfort by influencing the mental, emotional and social states of a subject. For instance, in the comfort model developed by De Looze [20], emotion was mentioned as a factor with strong impact on comfort. Ahmadpour et al. [21] also identified the strong correlation between the state of emotion and the perceived comfort of passengers in aircraft. It is also believed that bad odors from a neighbor in a closed space, e.g. aircraft cabin, can cause a negative effect on the perceived comfort [22].

However, the relations between different scents and the perceived comfort/discomfort of air passengers over time are not fully explored. For instance, the ability to distinguish a particular odor after a prolonged exposure (olfactory fatigue) regarding comfort is not clear yet, as the limited space inside an aircraft cabin makes it difficult for odors to dissipate and it is unknown at which point humans get used to a scent after in an environment, thus cause olfactory fatigue [23]. The effects of different types of smells with different intensity on comfort are also not fully explored.

\section{Materials and methods}

The aim of this study is to explore relationships between exposure to scents and the perceived comfort over time. The study was conducted in a Boeing 737 fuselage and was designed to be a between-subject experiment. A total of 276 university students (154 females, 93males, 29 not mentioned) were invited to participate in the study. The students were divided into nine groups, and each group joined a session which lasted around 60 minutes. These nine sessions were carried out during three days with three sessions per day. The first session of each day were used as a control group, i.e. the researchers did not add a scent in this session. From the second session, scents were introduced. Due to its wide usage in aromatherapy, the pure essential oil was selected to produce the smell [12]. In the second session of each day, 4 drops (about $0.05 \mathrm{ml} / \mathrm{drop}$ ) of essential oils (brand: Holland $\&$ Barrett) were applied to each of three aromatherapy burners. These three identical burners were deployed in the front, the middle and the end of the fuselage cabin, respectively. In the third session of each day, 12 drops of essential oils were applied to double the perceived intensity of the smell. The number of drops was calculated based on Steven's power law [24], which describes the relation between the perceived changes $(\mathrm{P})$ and the actual changes of physical stimulus (I) as $P=K I^{a}$. Here $\mathrm{k}$ is a constant and for smell, it was set as 0.6. After the third session, the session with the most intensive scent used, of each day, a forced air ventilation was utilized to disperse the residual smell to prepare the experiment for the following day. Three types of scents, lavender, cedar and mandarin were used each day during the threeday experiment. Everyday only one type of scent in different intensity was used. Table 1 lists the setups and the schedule of the experiment. The reason of choosing these three scents is that there are indications that these scents have the function of improving 
Table 1

Experiment schedule

\begin{tabular}{lccc}
\hline & \multicolumn{1}{c}{$1^{\text {st }}$ day } & $2^{\text {nd }}$ day & $3^{\text {rd }}$ day \\
\hline Session 1 & No scent added & No scent added & No scent added \\
Session 2 & 15min break, change of groups & \\
\cline { 2 - 4 } & $\begin{array}{c}\text { Lavender (4 drops) } \\
\text { in each burner }\end{array}$ & $\begin{array}{c}\text { Cedar (4 drops) } \\
\text { in each burner }\end{array}$ & $\begin{array}{c}\text { Mandarin (4 drops) } \\
\text { in each burner }\end{array}$ \\
\cline { 2 - 4 } Session 3 & $\begin{array}{c}\text { Lavender (12 drops) } \\
\text { in each burner }\end{array}$ & $\begin{array}{c}\text { Cedar (12 drops) } \\
\text { in each burner }\end{array}$ & $\begin{array}{c}\text { Mandarin (12 drops) } \\
\text { in each burner }\end{array}$ \\
\hline
\end{tabular}

the mood by increasing the feeling of calm, relaxed and reducing stress [25].

The comfort/discomfort questionnaire [26] (11 point scale; $0=$ no comfort/discomfort, $10=$ extreme comfort/discomfort) and the PrEmo questionnaire [27] were used in this study to get an indication of the perceived comfort/discomfort and the emotion. PrEmo questionnaire is a non-verbal self-reported questionnaire contains in total fourteen emotions including seven positive emotions and seven negative emotions expressed by a cartoon character [27]. The division of emotions was also mentioned by Russell [28] that all the emotions can be placed in the scale of arousal(high-low) and valence(positive-negative). The procedure of each session was the same, in which the host researcher welcomed the participants and then acquired a signed informed consent form from each subject. The participants were then seated and completed a comfort/discomfort questionnaire and a PrEmo questionnaire. After filling in the questionnaires, participants were asked to sit and use their mobile phone. They could do the task they wanted (e.g. texting, reading, gaming). Every 10-15 minutes, they had a chance to walk in the cabin to avoid the occurrence of physical complaints on comfort and discomfort [29]. Each session took 60 minutes. At the end of the session, the participants were asked to complete the second set of questionnaires, which was the same as the first set. To avoid allergy, participants were informed of the scents prior to the experiment, so they can register themselves into control groups.

In the process of analyzing the data collected from the experiment, missing data (dependent on the question 11-18 out of 276 answers were missing) were excluded for the analysis. In the interpretation of the emotions in this study, the fourteen emotions were divided into two groups, either positive emotions or negative emotions according to Desmet and Wassink [27]. All negative emotions were assigned as -1 while the positive emotions were set as 1 . Data sets were grouped regarding completion time,
Table 2

Weather conditions during the experiment

\begin{tabular}{lccc}
\hline & Day 1 & Day 2 & Day 3 \\
\hline Temperature & 17.5 & 15 & 17 \\
Humidity & $94 \%$ & $80 \%$ & $88.5 \%$ \\
Atmosphere & 1005 mbar & $1010 \mathrm{mbar}$ & $998 \mathrm{mbar}$ \\
pressure & & & \\
\hline
\end{tabular}

scents, intensity, time and genders. The normality of the data was then checked using the Shapiro-Wilk test [30] with and without log transformation. Since the distribution of data did not fit the normal distribution, the Mann-Whitney U test was selected to evaluate the dependence between data sets. Principal components analysis(PCA) [31] was conducted regarding the changes of comfort and discomfort. There were rainfalls with varied precipitation from time to time during the three days and the temperature on the three days were $17.5^{\circ} \mathrm{C}, 15^{\circ} \mathrm{C}$ and $17^{\circ} \mathrm{C}$ respectively while the humidity were $94 \%, 80 \%$ and $88.5 \%$. Detailed information regarding weather can be found in Table 2. Considering the importance of the humidity and temperature on perceived comfort $[4,5]$, data of control groups was not combined.

\section{Results}

Table 3 shows the means and standard deviations of scores of comfort and discomfort in 9 sessions. Two sets of data with statistically significant differences $(\mathrm{p}<0.05)$ are linked by lines.

Control groups scored quite scattered in the evaluation of comfort at beginning of the three sessions $(5.19 \pm 1.85,5.71 \pm 1.49,4.55 \pm 1.89)$. However, when the scents were introduced, the levels of perceived comfort often dropped over time. Compared with the control groups, the smell of mandarin, no matter strong or weak, significantly raised the comfort at the beginning of the experiment $(\mathrm{p}<0.05)$. For the other 2 scents (lavender and cedar), no signifi- 
Table 3

Changes of scores of comfort and discomfort in nine sessions (scale 0-10)

\begin{tabular}{|c|c|c|c|c|c|c|}
\hline & Scents & $\mathbf{N}$ & $\begin{array}{l}\text { Mean } \\
(0 \mathrm{~min})\end{array}$ & $\begin{array}{l}\text { SD } \\
(0 \mathrm{~min})\end{array}$ & $\begin{array}{l}\text { Mean } \\
\text { (60min) }\end{array}$ & $\begin{array}{l}\text { SD } \\
(60 \mathrm{~min})\end{array}$ \\
\hline \multirow[t]{9}{*}{ Comfort } & Control 1 & 36 & 5.19 & 1.85 & 5.33 & 1.71 \\
\hline & Weak lavender & 30 & $5.70_{7}$ & 1.51 & 4.93 & 1.74 \\
\hline & Strong lavender & 31 & 4.97 & 1.82 & 4.58 & 2.14 \\
\hline & Control 2 & 33 & 5.71 & 1.49 & 5.12 & 1.52 \\
\hline & Weak cedar & 33 & 5.76 & 1.62 & 5.64 & 1.75 \\
\hline & Strong cedar & 33 & 5.53 & 1.42 & 5.09 & 2.11 \\
\hline & Control 3 & 29 & 4.55 & 1.89 & 4.89 & 1.99 \\
\hline & Weak mandarin & 24 & 5.60 & 1.94 & 5.17 & 1.99 \\
\hline & Strong mandarin & 18 & 5.67 & 1.14 & 5.56 & 1.62 \\
\hline \multirow[t]{9}{*}{ Discomfort } & Control 1 & 36 & 3.78 & 1.64 & 4.08 & 2.03 \\
\hline & Weak lavender & 30 & 3.37 & 1.65 & 4.47 & 2.08 \\
\hline & Strong lavender & 31 & 3.97 & 2.01 & 4.817 & 1.94 \\
\hline & Control 2 & 33 & 3.62 & 1.72 & 4.15 & 1.97 \\
\hline & Weak cedar & 33 & 3.32 & 1.55 & 4.00 & 1.82 \\
\hline & Strong cedar & 33 & 4.26 & 1.81 & 4.94 & 2.00 \\
\hline & Control 3 & 29 & 4.87 & 1.93 & 5.00 & 1.90 \\
\hline & Weak mandarin & 24 & 4.16 & 2.06 & 4.50 & 2.17 \\
\hline & Strong mandarin & 18 & 3.56 & 1.20 & $4.00 」$ & 2.06 \\
\hline
\end{tabular}

cant differences were found when compared with the control groups.

In all sessions, discomfort increased after $60 \mathrm{~min}$ utes. Lavender and cedar led to higher discomfort scores compared with the control groups. The intensities regarding lavender and cedar, high intensity led to higher discomfort scores at both the beginning and the end of the experiment. However, the effect of mandarin is different where participants reported lower discomfort scores on high intensity smell.

For males, significant differences were found between control group $2(4.60 \pm 1.65)$ and the strong cedar group $(4.11 \pm 2.52)$ and between the weak cedar group (mean $4.07 \pm 1.94$ ) and the strong cedar group $(4.11 \pm 2.52)$ at the end of the experiment regarding discomfort. Differences were also found between control group $3(4.92 \pm 2.06)$ and the weak mandarin group $(5.63 \pm 1.67)$ and control group $3(4.92 \pm 2.06)$ and the strong mandarin group $(5.67 \pm 1.32)$ on comfort at the beginning and between control group $3(4.85 \pm 1.91)$ and the strong mandarin group $(3.67 \pm 1.58)$ on discomfort at the beginning. We did not find any significant differences between the female groups although the number of female participants was larger.

Figure 1 ( $\mathrm{a}, \mathrm{b}$ and $\mathrm{c}$ ) present the relations between the changes of comfort and the changes of discomfort over time regarding all three scents, respectively. The PCA showed that for control group 1, the first component (PC1) explains $56.06 \%$ of the variation and the second (PC2) explains $43.95 \%$. For the weak lavender group, $\mathrm{PC} 1$ explains $84.59 \%$ of the variation and the PC2 explains $15.50 \%$. For the strong lavender group, PC1 explains $76.91 \%$ while PC2 explains $23.09 \%$. In both scenarios with light and strong smell used, PC1 increases while PC2 decreases, the difference between two components becomes larger. This trend is similar on the second and the third days showing that the scores were more linear in the scenarios with scents, compared to control groups, with the exception of the light smell in day 2 . The exact values of different components are shown in Fig. 1. 
(a) $1^{\text {st }}$ day

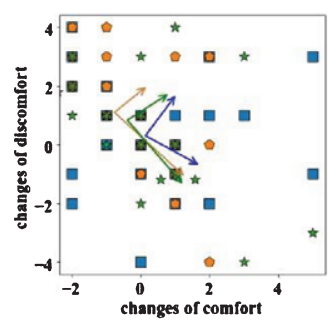

Control a

Light smell

Strong smell
$56.05 \% / 43.95 \%$

$84.59 \% / 15.50 \%$

$76.91 \% / 23.09 \%$ (b) $2^{\text {nd }}$ day

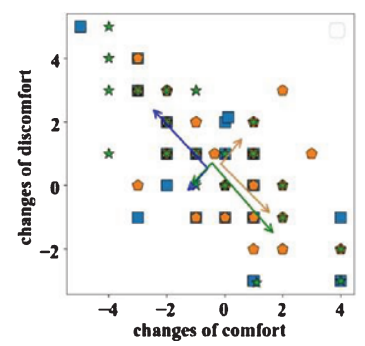

$87.55 \% / 12.45 \%$

$81.36 \% / 18.64 \%$

$90.48 \% / 9.52 \%$ (c) $3^{\text {rd day }}$

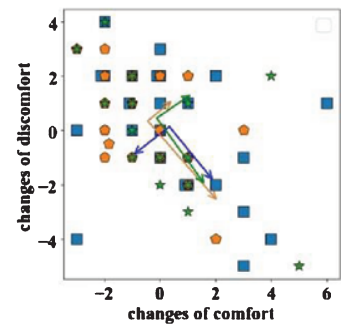

$69.54 \% / 30.46 \%$

$91.81 \% / 8.19 \%$

$79.35 \% / 20.65 \%$

Fig. 1. The changes in comfort vs the changes in discomfort (variance of PC1/variance of PC2).

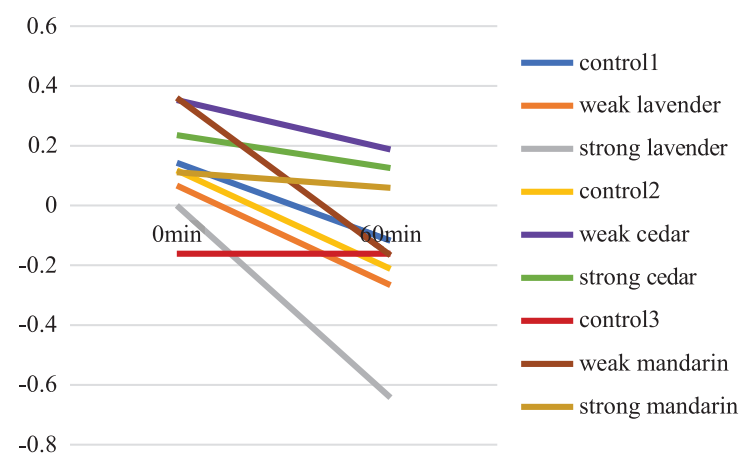

Fig. 2. Average values of emotion at the beginning and the end of the experiment.

Figure 2 shows the emotions of nine sessions at the beginning and the end of the experiment. Often, the changes were negative except for control group 3. For weak cedar, strong cedar and strong mandarin, the score decreased less and ended with positive emotion. For participants exposed to lavender, no matter strong or weak, their emotion changed most towards the negative side. No significance was found among scents at the beginning of the experiment. Among all scenarios, a significant change from beginning $(0 \pm 1.02)$ to the end $(-0.64 \pm 0.78)$ was found for strong lavender only. For different types of scents, significant differences were found between control $1(-0.09 \pm 1.01)$ and strong lavender $\quad(-0.64 \pm 0.78)$ groups, strong lavender $(-0.64 \pm 0.78)$ and strong cedar $(-0.13 \pm 1.01)$ groups, strong lavender $(-0.64 \pm 0.78)$ and strong mandarin $(0.06 \pm 1.03)$ groups at the end of the experiment. Compared to the groups using other two scents, the strong lavender group gave the lowest score regarding emotion at the end of the experiment.

\section{Discussion}

\subsection{Effect of scent on comfort/discomfort}

Effects of scents on comfort are dependent on the types of scents, the intensity and the gender of participant, and sometimes, no effect could be found. For discomfort the variation was less.

In all circumstances, comfort dropped and discomfort increased after 60 minute exposure to sitting in an aircraft seat which is in accordance with the findings of Vink et al. [32]. Scores on comfort were very dispersed, which could be a result of the variety of personal preference on scents.

Regarding the types of the scents, lavender scored quite negative when calculating the average for discomfort, and also scored negative for emotion. However, it was found that lavender fragrance blend had a significant transient effect of improving mood and increasing a relaxed feeling in an earlier study [33]. The mixture of the context smell in the cabin and the lavender smell might even have caused this effect on the passengers' perception of comfort/discomfort. Slightly better results on both comfort and discomfort were achieved with mandarin. Mandarin could have helped to achieve a better score on comfort since it is linked to food. Positive effects on comfort have been found when food is served in cabin. At the same time, citral in mandarin may help to create a relaxed, pleasant and energetic feeling [34]. Cedar scent in different intensities influenced discomfort differently but there was no difference found between groups with cedar and control groups. The reason could be that the sense and preference are very personal while the smell creates a trend of homogeneity. 


\subsection{Effect of scent on emotion}

Changes in emotion for the three control groups were quite different, especially on the $3^{\text {rd }}$ day. The atmosphere pressure on the third day ( $998 \mathrm{mbar}$ ) was the lowest in three days (the other two days were 1005 mbar \& 1010mbar), which may be the reason for the difference. In the study done by BurdackFreitag et al. [35], it was also observed that odor thresholds of flavorants increase at low pressure conditions. There were few exceptions in the experiment and the odor spectrum of drinks changed differently but it was clear that atmosphere pressure influence the odor thresholds.

In most scenarios, there was no obvious distinction between groups where scents were added and between control groups. This can be a result of the existence of the context smell inside the cabin since the context smell cannot be removed and new scents were mixtures of context smell and added scents. The odor compounds of context smell in cabin still had a major role in the experiments, especially in scenarios with low-intensity scents. Using strong lavender is the only scent which had a significant drop on emotion after the experiment, using weak lavender was significantly better than strong lavender. This suggested that intensity can play an important role on the perception of smell since intensity of a certain smell can strongly influence the feeling of pleasantness [36].

In most circumstances, negative effects were shown both on overall comfort/discomfort and emotion, which shows some correlation between the effects on emotion and comfort as described in previous studies [20, 21, 37].

\subsection{Gender difference regarding smells}

Scent appeared to have influenced males more than females. However, results of previous studies reported that females have more neuronal and nonneuronal cells in their olfactory bulb than males, which might indicate a higher sensitivity to smell [38]. It could be that although females smell these scents, these scents do not influence their comfort or discomfort in an airplane sitting for an hour. However, this should be further researched.

\subsection{Limitations}

The activities for the simulated flight were not exactly the same as in a normal flight. In this experiment the passengers did move in the cabin in order to reduce the impact of physical complaints on overall comfort/discomfort. This (more variation) could have influenced the outcome because this is not often seen in a normal flight situation. Keeping participants seated the entire experiment could be an option in the future to be closer to a real scenario.

To prevent any potential allergy, we informed the participants about the types of essential oils that will be used before the experiment. Outcomes of the experiment might be different if the participants were not informed before.

\subsection{Design implications}

During data analysis, large variations in outcomes were observed. Although all the participants were in the same environment, the perceived smell differed, which is related to odor receptors due to gene differences [39]. This indicates that forcing passengers to share the same odors in the air might not be a solution to please everyone. The design strategy should not be to "design for average" when utilizing scents in an airplane cabin [40]. This strategy is not typical for scent. The amount of personalized "mass-produced" items is increasing and different brands are seeking opportunities to be more attractive to consumers by offering personalized products as well as services [41]. In the car industry, a gradual change towards accommodating individuality is available [42]. In present day aircrafts, many passengers have the same seat and limited choice of food. In passenger experience research, more differentiation is shown, following the same trend as the car industry. Compared with individual transportation systems, the large diversity in passengers does not make personalization a simple task. However, actions have been already taken, i.e. ordering your food online before a flight. The use of smell in cabin could also be personalized, at least partly personalized. The differences in human olfactory systems between individuals makes personalization in scents more necessary.

\section{Conclusion}

Smell influences the perception of comfort and discomfort in an aircraft cabin. The effect of smell differentiates over time and does not only contribute to the first sight comfort/discomfort but also had an impact at the end of the experience in short haul trips. In this experiment the trend of decreasing comfort or increasing discomfort over time did not change by 
adding scents. In this case, adding scents did make the correlation between change of comfort and change of discomfort more linear. The effects of different scents vary person-to-person and adding more scent to make it stronger was not helpful to achieve better results. Emotion changes were found with different scents and may have resulted in different perceptions of overall comfort/discomfort. It is recommended for future designs regarding diverse individual preferences, to personalize scents or smell in airplane cabins.

\section{Acknowledgment}

This research is partly funded by EU Horizon 2020 CleanSky COMFDEMO (COMFort in the cabin DEMOnstrator) project under grant agreement 831992. The authors would like express their appreciation to S.Udomboonyanupap and I. Ruiter for their kind assistance during the experiment. The authors would also thank the anonymous reviewers for their valuable suggestions on this paper.

\section{Conflict of interest}

The authors declare that the research was conducted in the absence of any commercial or financial relationships that could be construed as a potential conflict of interest.

\section{References}

[1] Schaefer M. Development of a Forecast Model for Global Air Traffic Emissions [Internet]. 2012 [cited 2019 Dec 14]. Available from: https://www.researchgate.net/publication/259895835

[2] Bouwens J, Hiemstra-van Mastrigt S, Vink P. Ranking of Human Senses in Relation to Different In-flight Activities Contributing to the Comfort Experience of Airplane Passengers. Int J Aviat Aeronaut Aerosp. 2018;

[3] Vink P, Hallbeck S. Editorial: Comfort and discomfort studies demonstrate the need for a new model. Appl Ergon. 2012;43(2):271-6.

[4] Krist R. Modellierung des Sitzkomforts - eine experimentelle Studie. Katholischen Universität Eichstätt; 1993.

[5] Bubb H. Automobilergonomie. In: Springer Vieweg. Wiesbaden; 2015.

[6] Bubb R. Sitting comfort. In: IQPC aircraft interior innovation. Hamburg; 2008.

[7] Amoore J. Odor theory and odor classification. In: Theimer ET, editor. Fragrance chemistry: the science of the sense of smell. New York: Academic Press; 1982. pp. 27-76.
[8] Russell MJ. Human olfactory communication. Nature. 1976;260(5551):520-2.

[9] Kako H, Fukumoto S, Kobayashi Y, Yokogoshi H. Effects of direct exposure of green odour components on dopamine release from rat brain striatal slices and $\mathrm{PC} 12$ cells. Brain Res Bull. 2008;75(5):706-12.

[10] Savic I. Imaging of brain activation by odorants in humans. Curr Opin Neurobiol. 2002;12(4):455-61.

[11] Angelucci FL, Silva VV, Dal Pizzol C, Spir LG, Praes CEO, Maibach H. Physiological effect of olfactory stimuli inhalation in humans: An overview. Int J Cosmet Sci. 2014;36(2):117-23.

[12] Kiecolt-Glaser JK, Graham JE, Malarkey WB, Porter K, Lemeshow S, Glaser R. Olfactory influences on mood and autonomic, endocrine, and immune function. Psychoneuroendocrinology. 2008;33(3):328-39.

[13] Ehrlichman H, Bastone L. Olfaction and Emotion. In: Science of Olfaction. New York, NY: Springer New York; 1992. pp. 410-38.

[14] Gibbons B. The intimate sense of smell. Natl Geogr Mag. 1986;170:324-61.

[15] Lieff B, Alper J. Aroma driven: On the trail of our most emotional sense. Health (Irvine Calif). 1988;20:62-7.

[16] Krusemark EA, Novak LR, Gitelman DR, Li W. When the Sense of Smell Meets Emotion: Anxiety-State-Dependent Olfactory Processing and Neural Circuitry Adaptation. J Neurosci. 2013;33(39):15324-32.

[17] Gaby JM, Zayas V. Smelling is telling: Human olfactory cues influence social judgments in semi-realistic interactions. Chem Senses. 2017;42(5):405-18.

[18] Baron RA. The Sweet Smell of... Helping: Effects of Pleasant Ambient Fragrance on Prosocial Behavior in Shopping Malls. Personal Soc Psychol Bull [Internet]. 1997 May 2 [cited 2019 Dec 2];23(5):498-503. Available from: http://journals.sagepub.com/doi/10.1177/014616729723 5005

[19] van Nieuwenburg D, de Groot JHB, Smeets MAM. The subtle signaling strength of smells: A masked odor enhances interpersonal trust. Front Psychol. 2019;10(AUG):1-10.

[20] De Looze MP, Kuijt-Evers LFM, Van Dieën J. Sitting comfort and discomfort and the relationships with objective measures. Ergonomics. 2003;46:985-97.

[21] Ahmadpour N, Robert J-M, Lindgaard G. Exploring the cognitive structure of aircraft passengers, emotions in relation to their comfort experience. KEER2014 Proc 5th Kanesi Eng Emot Res Int Conf Linköping; Sweden; June 11-13. 2014;(100):387-94.

[22] Vink P, Brauer K. What Every Manufacturer and Airline Should Know about Comfort. In: Aircraft interior comfort and design. 2011. pp. 10.

[23] Seppanen OA, Fisk WJ, Seppänen OA. Summary of Human Responses to Ventilation [Internet]. [cited 2019 Dec 5]. Available from: https://escholarship.org/uc/item/64k2p4dc

[24] Stevens SS. On the psychophysical law. Psychol Rev. 1957;64(3):153-81

[25] Schneider R. There Is Something in the Air: Testing the Efficacy of a new Olfactory Stress Relief Method (AromaStick®). Stress Heal. 2016;32(4):411-26.

[26] Vink P, Bazley C, Kamp I, Blok M. Possibilities to improve the aircraft interior comfort experience. Appl Ergon. 2012; 43(2):354-9.

[27] Desmet P, Wassink P. Delft Institute of Positive Design - PrEmo (Emotion Measurement Instrument) [Internet]. [cited 2019 Dec 5]. Available from: https://diopd.org/ premo/ 
[28] Russell JA. A circumplex model of affect. J Personal Soc [Internet]. 1980 [cited 2020 Apr 28]; Available from: https://psycnet.apa.org/journals/psp/39/6/1161/

[29] Mara Bazley C, Bazley C, Nugent R, Vink P. Patterns of Discomfort Robomate-Modular Exoskeleton for Industry View project Patterns of Discomfort. Artic J Ergon [Internet]. 2015 [cited 2019 Dec 2]; Available from: http://dx.doi.org/10.4172/2165-7556.1000136

[30] Shapiro SS, Wilk MB. An analysis of variance test for normality (complete samples). Biometrika. 1965;52(3-4):591611.

[31] Dunteman G. Principal components analysis. California: Sage Publications; 1989.

[32] Vink P. The sweetness of discomfort: Designing the journey. Delft: Delft University of Technology; 2014.

[33] Field T, Diego M, Hernandez-Reif M, Cisneros W, Feijo L, Vera Y, et al. Lavender fragrance cleansing gel effects on relaxation. Int J Neurosci. 2005;115(2):207-22.

[34] Jin L. Influence of odor intensity and mood on hedonic reactions to aroma compounds in a multi-ethnic sample of young adults. Graduate School-New Brunswick Rutgers; 2015.

[35] Burdack-Freitag A, Bullinger D, Mayer F, Breuer K. Odor and taste perception at normal and low atmospheric pressure in a simulated aircraft cabin. $\mathrm{J}$ fur Verbraucherschutz und Leb. 2011;6(1):95-109.
[36] Moskowitz HR, Dravnieks A, Gerbers C. Odor intensity and pleasantness of butanol. J Exp Psychol. 1974;103(2):21623.

[37] Vink P, Overbeeke CJ, Desmet PMA. Comfort Experience. In: Comfort and design: principles and good practice. FL: CRC Press; 2005. pp. 1-12.

[38] Oliveira-Pinto AV, Santos RM, Coutinho RA, Oliveira LM, Santos GB, Alho ATL, et al. Sexual Dimorphism in the Human Olfactory Bulb: Females Have More Neurons and Glial Cells than Males. Ravel N, editor. PLoS One. 2014;9(11):e111733.

[39] Logan DW. Do you smell what i smell? Genetic variation in olfactory perception. In: Biochemical Society Transactions. Portland Press Ltd; 2014. pp. 861-5.

[40] Clarkson PJ, Coleman R, Keates S, Lebbon C. Inclusive Design:Design for the Whole Population. Inclusive Design. Springer London; 2003.

[41] Kasriel-Alexander D. Top 10 Global Consumer Trends for 2017 [Internet]. 2017 [cited 2019 Dec 5]. Available from: https://go.euromonitor.com/white-paper-2017top-10-global-consumer-trends-EN.html

[42] Tractinsky N, Abdu R, Forlizzi J, Seder T. Towards personalisation of the driver environment: investigating responses to instrument cluster design. Int J Vehicle Design. 2011; Vol. 55. 